\title{
THREE DIMENSIONAL CHANGES OF ALVEOLAR BONE AFTER FLAPLESS IMMEDIATE IMPLANT PLACEMENT
}

\author{
Ahmed A.H. El-Feky *
}

\begin{abstract}
Objectives: The aim of this study was to evaluate alveolar bone dimensional changes after flapless immediate implant placement clinically and radiographically.

Patients and methods: Thirty-two Patients were divided into two groups; control (flap group): received flapped immediate implants combined with xeno-graft, Test (flapless group): received flapless immediate implants combined by xeno-graft. Evaluation includes presence of infection, wound dehiscence, implant exposure, graft exposure or loss, soft tissue dehiscence and implant stability.
\end{abstract}

Results: According to the statistical analysis has been shown that in flapless group the buccal and palatal bone height has minimal statistical significant than the flap group $(\mathrm{p}<0.001)$. Also, the bone width at baseline $(2,4,6 \mathrm{~mm})$ shown that in flap group there is a minimal statistical significant than the flapless group $(\mathrm{p}<0.001)$. Both group showed a statistically a significant increase in mean implant stability measurements at 6 months.

Conclusion: According to the results of this study could concluded that the flapless technique has been documented to be a simpler procedure as compared to "open flap" technique which preserve alveolar bone with immediate dental implants in the esthetic zone of the maxilla after tooth extraction. Also, several advantages achieved by flapless technique such as preservation of soft tissue architecture, intact periosteum maintains a better blood supply, thus reducing the likelihood of early bone resorption or promitting bone healing.

KEYWORDS: Immediate implant, flapless technique, ridge dimensional changes, Bovine bone graft substitute (BBGS).

\section{INTRODUCTION}

Dental implants are a consolidated treatment for missing teeth replacement that allows the restoration of chewing function, language and aesthetics ${ }^{(1)}$.
Osseo integration is the primary biological and biophysical process by which dental implant therapy is predictably effective in replacing missing teeth ${ }^{(2-3)}$. Traditionally, compromised teeth are

* Assistant Professor of Oral and Maxillofacial Surgery Department, Faculty of Oral and Dental Medicine,Cairo, Boys, AlAzhar University 
removed and the extraction sockets allowed to heal for several months before dental implants are placed. However, resorption of the alveolar ridge after tooth extraction can significantly reduce the remaining bone volume and compromise the favorable implant positioning required for an optimal prosthetic restoration. Such an aspect is even more pronounced in the anterior maxilla, where ridge resorption is more pronounced in the buccal wall, which leads to an unfavorable bucco-lingual discrepancy between implant and prosthesis ${ }^{(4,5)}$.

Immediate implant placement after extraction is a one-step procedure in which the implant must be placed after tooth extraction with no healing time ${ }^{(6)}$.

Immediate implant placement can reduce the number of clinical visits and surgical procedures compared to delayed implant placement because the patient's morbidity decreases and in some cases allows immediate recovery ${ }^{(7,8)}$. Extensive bone loss after immediate implantation can jeopardize osseointegration or raise aesthetic concerns, especially in the aesthetic zone of the maxilla, which is often characterized by a thin buccal plate ${ }^{(9)}$. It has been suggested that immediate implant placement preserves the dimensions of the alveolar bone. However, recent experimental studies and clinical studies do not support this concept and show significant changes in the dimensions of the bone ridge at the immediate implant operation site ${ }^{(10)}$. The buccal dimensional change is usually greater than that of the lingual or palatal dimension ${ }^{(11,12)}$. An experimental study showed that the facial socket wall, which consists almost entirely of bundle bones, can possibly be reabsorbed in the vertical and horizontal planes (13). This crestal bone resorption can lead to a recession of the facial mucosa. It has been suggested that an interruption of the vascular supply to the facial bone caused by lifting the surgical flap could be an important factor ${ }^{(14)}$.

Various techniques of immediate flap elevation implantation have already been described, However, increased bone loss and collapse of the interproximal papilla, which can lead to recession of the gingiva, destruction of the papilla, and resorption of the crestal bone ${ }^{(15)}$. A flapless approach could minimize buccal bone augmentation since the blood supply from the periosteum remains unchanged ${ }^{(16,17)}$. The aim of this study was to evaluate clinically and radiographically alveolar bone dimensional changes after flapless immediate implant placement.

\section{PATIENTS AND METHODS}

The study included thirty-two patients. All patients had non restorable tooth in the maxillary esthetic zone and needed immediate implant placement. The patients were selected from the outpatient clinics of the Department of Oral and Maxillofacial Surgery at the Dental Faculty of AlAzhar University Boys Cairo. The patients were divided randomly into two groups:

Control (flap group): which include sixteen patients that were received flapped immediate implants replacing non restorable tooth in the maxillary esthetic zone with placement of healing abutment at the day of surgery combined with grafting of the gap between the socket wall and the implant by xeno graft, the implants are conventionally loaded 6 months later. Test (flapless group): Include sixteen patients that were received flapless immediate implants replacing non restorable tooth in the maxillary esthetic zone with placement of healing abutment at the day of surgery combined with grafting of the gap between the socket wall and the implant by xeno-graft, the implants are conventionally loaded 6 months later. Selection of the patients was done according to inclusion criteria, the patients were over 18 years, had non-restorable tooth in the maxillary aesthetic zone and good oral hygiene. The exclusion criteria included, all local or systemic diseases, conditions or drugs that impair healing or osseointegration and can affect the periodontium (uncontrolled systemic disorder 
such as uncontrolled diabetes mellitus, autoimmune disease, radiation therapy and chemotherapy), Smokers, presence of any type of acute infection, any clinical signs of dehiscence or window defects affecting the walls of the facial socket, bruxism and parafunctional habit, inability or unwillingness to return for follow-up visits and pregnancy.

In accordance with Declaration of the Helsinki, written informed consent was taken from all patients, and the local ethics review committee of the Faculty of Dental Medicine at Al Azhar University for Boys approved the study.

\section{Surgical protocol}

\section{Preoperative assessment}

Each patient was inspected to make sure that is indicated to be candidate of this study regarding to: medical history, dental history and clinical examination by: Inspection and palpation of muscles of mastication, tempromandibular joint and lymph nodes to check for any disorders, Inspection to assess the general oral hygiene, occlusion, condition of the existing teeth and oral mucosa and available inter arch space, presence of infection and gingival biotype. Also, preoperative cone beam computed tomography (CBCT) was performed for all patients to evaluate: the tooth root and its configuration, vital structure related to the tooth, vertical and horizontal dimensions of the alveolar bone to detect the implant fixture width and length.

\section{Surgical procedure}

All patients were operated under local local anesthesia using infiltration of articaine chlorhydrate $4 \%$ containing adrenaline at a concentration 1:100000, France). In flapped group circular incision was made by blade \#15, full mucoperiosteum flap was elevated labially as envelop flap by periosteal elevator. While, in flapless group circular incision was made without any reflection.
Atrumatic extraction was started by using periotome to sever periodontal tissue attachment around the root and to luxate the tooth. Atraumatic extraction was carried out. Immediately after the extraction a CBCT was taken in order to evaluate the integrity of the facial wall of the socket and to superimpose post extraction image with postoperative 6 months of follow up. Successive sequential implant drilling was done according to implant diameter and suitable length as preoperative planning. After proper osteotomy is prepared, the implant was inserted in the prepared socket in vertical plane and screwed manually to reach the maximum manual torque then continue with ratchet wrench to seat the implant into its final position, implant shoulder was placed 1.5 to $3 \mathrm{~mm}$ apical to gingival margin. In two groups after implant placement, bovine bone substitute with biocompatible collagen type 1 was filled in the gap between the implant body and the socket wall. Then healing abutments were selected and positioned. The height of healing abutment was selected in a way to ensure that there was no functional loading of the implant. Fig. (1)

\section{Postoperative care}

Patient asked to do plaque removal at the exposed abutment with soft-bristled toothbrush and rinse with an antiseptic mouthwash, antibiotic and anti-inflammatory regimen.

\section{Postoperative clinical evaluation}

All patients was be followed clinically at the following interval; immediate, 3 days, one week, two weeks, three months and six month's postoperatively to evaluate the following parameters, wound healing, suture breakdown and dehiscence, implant and /or graft exposure, presence or absence of infection and implant stability.

\section{Postoperative radiographic evaluation}

Radiographic examination in the follow up period after 6 months was achieved by cone beam 


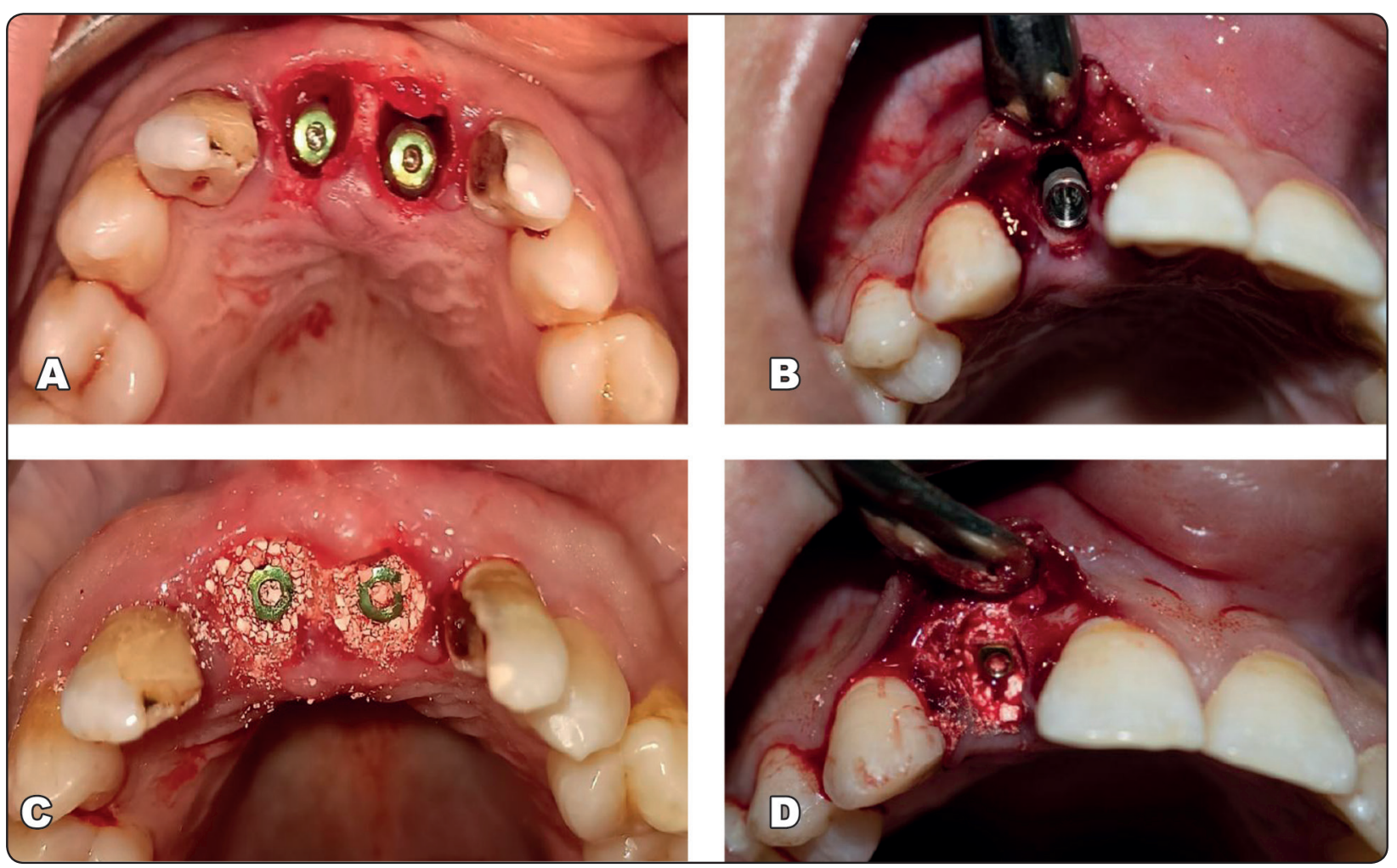

Fig. (1) Showing A: Implant in its final position flapless group, B: Implant in its final position in flapped group, C: grafting bovine bone substitute with biocompatible collagen type 1 within a flapless group, D: grafting bovine bone substitute with biocompatible collagen type 1 in flapped group.

CT scan (Scanora 3d, Sordex, Finland) to superimpose CBCT1 post extraction and CBCT2 measurements by 3D imaging software (Planmeca Romexis) that used in this study. Data was collected, changes was occurred in vertical and horizontal alveolar bone dimension was evaluated and documented by reference points and lines at base line* from two groups to detect the difference. To set a reference point, the vertical reference line was drawn in the centre of the extraction socket crossing the apical reference point. The horizontal reference line was drawn perpendicular to the vertical line crossing the apical reference point in the centre of

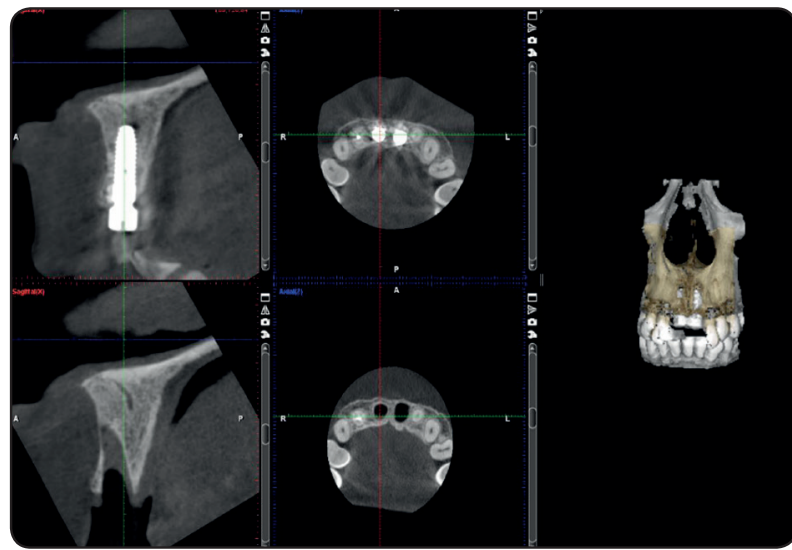

Fig. (2) Superimposition of CBCT 1 and CBCT 2 in flapless group the extraction. Fig. $(2,3,4)$

* The most apical point of the extracted socket. 


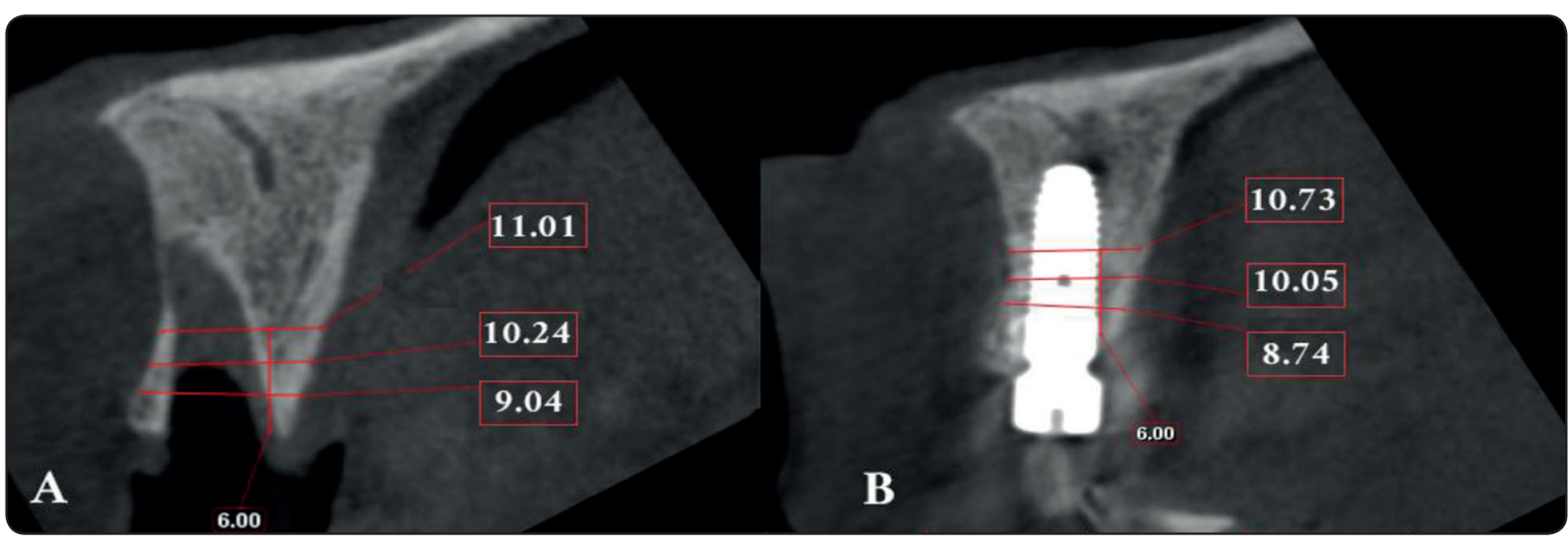

Fig. (3) Flapless group A: ridge width immediately post extraction, B: ridge width 6 months postoperative at $2 \mathrm{~mm}, 4 \mathrm{~mm}$ and $6 \mathrm{~mm}$ of height of the ridge.

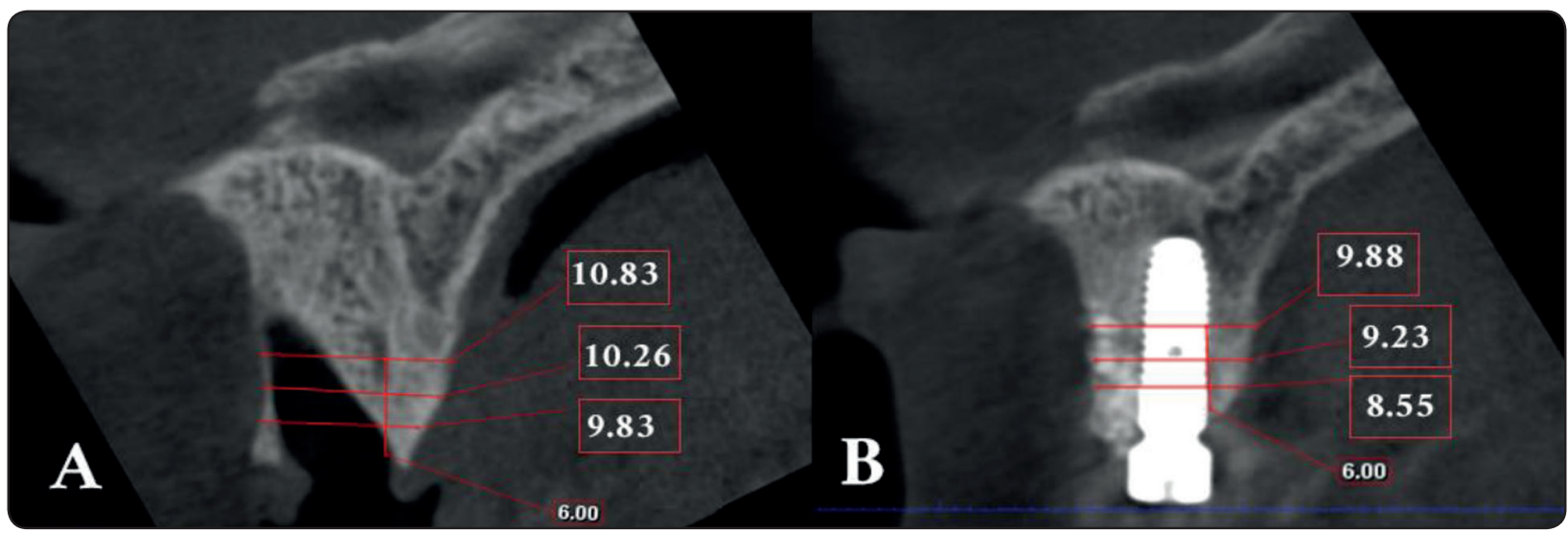

Fig. (4) Flapped group A: ridge width immediately post extraction, B: ridge width 6 month postoperative

\section{Statistical analysis of the data:}

Data was collected analyzed using Microsoft Excel software. Data was then imported into the Statistical Pacage for the Social Science (SPSS version 20.0) software for analysis.

\section{RESULTS}

\section{Demographic data}

The two groups had non restorable tooth in the maxillary esthetic zone who completed the follow up were included in the statistical analysis of this study. 16 patients ranged in age between $25.0-36.0$ years with a mean age of $30.81 \pm 4.07$ years for Control (flap) group and 16 patients ranged in age between 24.0 - 35.0 years with a mean age 30.87 \pm 3.88 years for Test (flapless) group, regarding to sex Control (flap) group had (37.5\% males and $62.5 \%$ females, while Test (flapless) group had $18.8 \%$ males and $81.3 \%$ females.

\section{Sample size calculation}

To study the influence of flap and flapless techniques on alveolar bone dimensions after immediate implant placement, an independent $t$ test will be used for comparison. According to a previous study by Mazzocco et al ${ }^{(1)}$, the mean difference in palatal height was $0.1433 \pm 1.65$ and $0.915 \pm 1.35$ in flap and flapless respectively. A medium effect size of approximately 0.46 is expected. 


\section{CBCT postoperative outcomes}

There was significant differences in all dimensions of bone height in the two groups was recorded which was measured by percentage of change throughout the follow up intervals.

\section{Bone height}

Buccal bone height, regarding change: there was a statistically a significant difference $\left(\mathrm{p}<0.001^{*}\right)$ in mean buccal bone height in the two groups. The flapless group showed a decrease $(0.09 \mathrm{~mm})$ change than the flap $(1.13 \mathrm{~mm})$. Palatal bone height, regarding change: there was a statistically a significant difference $\left(\mathrm{p}<0.001^{*}\right)$ in mean palatal bone height in the two groups. The flapless group showed an increase change $(0.91 \mathrm{~mm})$ than flap $(0.21 \mathrm{~mm})$. Table (1)

\section{Ridge width}

At $2 \mathrm{~mm}, 4 \mathrm{~mm}$, and $6 \mathrm{~mm}$, Control (flap) group showed a statistically significant decrease in mean ridge width measurements at 6 months $(\mathrm{p}<0.001 *)$.

At $2 \mathrm{~mm}, 4 \mathrm{~mm}$, and $6 \mathrm{~mm}$, Test (flapless) group showed a statistically significant decrease in mean ridge width measurements at 6 months $(\mathrm{p}<0.001 *)$. Table (2) and Fig. (5)

\section{Implant stability}

Both group showed higher statistical significant in mean implant stability measurements at 6 months. Table (3)

\section{Clinical postoperative outcomes}

In this study, both groups had no infection, wound dehiscence, implant exposure, graft exposure or loss, or soft tissue dehiscence.

TABLE (1): Mean height and width values at baseline and 6 months

\begin{tabular}{|l|c|c|c|}
\hline & Control (flap) & Test (flapless) & p \\
\hline Buccal bone height & Mean \pm SD & Mean \pm SD & \\
Baseline & $21.19 \pm 0.75$ & & \\
6 months & $20.06 \pm 0.72$ & $19.44 \pm 0.72$ & $<0.001^{*}$ \\
Change (decrease) & $\mathbf{1 . 1 3} \pm \mathbf{0 . 0 6}$ & $19.35 \pm 0.72$ & $0.010^{*}$ \\
\hline Palatal bone height & & $\mathbf{0 . 0 9} \pm \mathbf{0 . 0 1}$ & $<\mathbf{0 . 0 0 1}^{*}$ \\
Baseline & $17.25 \pm 0.72$ & & \\
6 months & $17.04 \pm 0.72$ & $19.34 \pm 0.73$ & $<0.001^{*}$ \\
Change (decrease) & $\mathbf{0 . 2 1} \pm \mathbf{0 . 0 2}$ & $18.44 \pm 0.72$ & $<0.001^{*}$ \\
\hline
\end{tabular}

Data was expressed by using (Mean $\pm S D$.)

$t:$ Student t-test

p: $p$ value for comparing between the studied groups

*: Statistically significant at $p \leq 0.05$ 
TABLE (2): Comparison between the two groups according to ridge width

\begin{tabular}{|c|c|c|c|c|}
\hline Ridge width & Control (flap) $(n=16)$ & Test (flapless) $(n=16)$ & $\mathbf{t}$ & $\mathbf{p}$ \\
\hline \multicolumn{5}{|l|}{ At $2 \mathrm{~mm}$} \\
\hline Baseline & $9.83 \pm 0.68$ & $9.04 \pm 0.72$ & $3.184^{*}$ & $0.003 *$ \\
\hline 6 months & $8.55 \pm 0.72$ & $8.74 \pm 0.71$ & 0.763 & 0.452 \\
\hline Change (decrease) & $1.28 \pm 0.07$ & $0.30 \pm 0.01$ & 59.382* & $<0.001 *$ \\
\hline \multicolumn{5}{|l|}{ At $4 \mathrm{~mm}$} \\
\hline Baseline & $10.26 \pm 1.37$ & $10.24 \pm 0.72$ & 0.055 & 0.957 \\
\hline 6 months & $9.23 \pm 1.41$ & $10.05 \pm 0.72$ & 2.064 & 0.051 \\
\hline Change (decrease & $1.03 \pm 0.12$ & $0.19 \pm 0.01$ & $28.157 *$ & $<0.001 *$ \\
\hline \multicolumn{5}{|l|}{ At $6 \mathrm{~mm}$} \\
\hline Baseline & $10.83 \pm 2.12$ & $11.01 \pm 0.67$ & 0.318 & 0.754 \\
\hline 6 months & $9.88 \pm 2.01$ & $10.73 \pm 0.72$ & 1.598 & 0.127 \\
\hline Change (decrease) & $0.95 \pm 0.13$ & $0.27 \pm 0.08$ & $17.536 *$ & $<0.001 *$ \\
\hline
\end{tabular}

Data was expressed by using (Mean $\pm S D$.)

t: Student t-test

p: $p$ value for comparing between the studied groups

*: Statistically significant at $p \leq 0.05$

TABLE (3): Comparison between the two studied groups according to implant stability

\begin{tabular}{|l|c|c|c|c|}
\hline & $\begin{array}{c}\text { Control (flap) } \\
(\mathbf{n}=16)\end{array}$ & $\begin{array}{c}\text { Test (flapless) } \\
(\mathbf{n}=\mathbf{1 6})\end{array}$ & $\mathbf{t}$ & $\mathbf{p}$ \\
\hline Implant stability & & & & $<.839 *$ \\
$\quad$ Primary & $62.50 \pm 2.58$ & $66.69 \pm 1.25$ & $7.642 *$ & $<0.001 *$ \\
6 months & $66.87 \pm 2.22$ & $71.69 \pm 1.20$ & $4.038 *$ & $<0.001 *$ \\
Change(increase) & $4.38 \pm 0.50$ & $5.0 \pm 0.37$ & \\
\hline
\end{tabular}

Data was expressed by using (Mean $\pm S D$.) $t$ : Student t-test

p: $p$ value for comparing between the studied groups

*: Statistically significant at $p \leq 0.0$

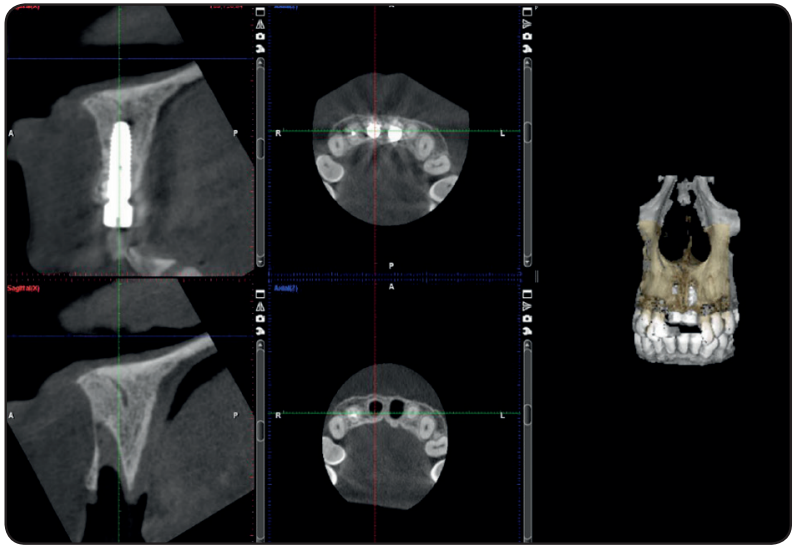

Fig. (5): Comparison between the two groups according to Ridge width height and bone change

\section{DISCUSSION}

Traditionally, access for implant placement has been by a flap approach. Studies have demonstrated that flap reflection often results in bone resorption around the natural teeth ${ }^{(18)}$. Postsurgical tissue loss from flap reflection has also been reported in the literature.

Recent studies have reported minimized access for implant placement by flapless approach ${ }^{(19)}$. The flapless technique has been documented to be a simpler procedure as compared to "open flap" 
technique and is associated with several advantages such as preservation of soft tissue architecture, improved patient comfort and satisfaction (20-24). Furthermore, the intact periosteum maintains a better blood supply, thus reducing the likelihood of early bone resorption ${ }^{(25)}$. However, flapless implant surgery has some limitations which include greater skill required on the part of surgeon to visualize anatomic landmarks and vital structures; the potential for thermal damage secondary to reduced access for external irrigation during osteotomy preparation; the increased risk of malposed angle or over or under drilling of the osteotomy site; a decreased ability to contour osseous topography when needed to facilitate restorative procedures and to optimize soft tissue contours and; most important the inability to manipulate soft tissues to ensure circumferential adaptation of adequate dimensions of keratinized gingival tissue around emerging implants ${ }^{(20)}$.

The choice of surgical procedure according to the literature depends upon its success rate, simplicity and experience of the operator while for the patient; comfort is an important criterion. Limited controlled data are available to evaluate the crestal bone height $(\mathrm{CBH})$ after flapless implant surgery. In addition, most crestal bone loss occurs in the early phase after implant placement. The purpose of this study was to evaluate alveolar Bone dimensional Changes after flapless immediate implant placement ${ }^{(26-28)}$.

An adequate bone housing of implants has been associated with long term peri-implant soft tissue stability and, in consequence, with an aesthetic outcome. For this reason, different strategies have been developed in order to minimize bone loss around implants. The results of this investigation show that immediate implant placement with simultaneous grafting does not entirely avoid bone resorption. Thus, a mean reduction of around 0.5 $\mathrm{mm}$ in height and width were observed ${ }^{(29)}$.

In this study, Buccal bone height, flapless group showed a significant decrease $(0.09 \mathrm{~mm})$ change than flap $(1.13 \mathrm{~mm})$. Palatal bone height, flapless group showed significant increase change $(0.91 \mathrm{~mm})$ than flap $(0.21 \mathrm{~mm})$. Ridge width, at $2 \mathrm{~mm}$, flapless group showed a significant decrease change $(0.30$ $\mathrm{mm})$ than flap $(1.28 \mathrm{~mm})$. At $4 \mathrm{~mm}$, flapless group showed a significant decrease change $(0.19 \mathrm{~mm})$ than flap $(1.03 \mathrm{~mm})$. At $6 \mathrm{~mm}$, flapless group showed a significant decrease change $(0.27 \mathrm{~mm})$ than flap $(0.95 \mathrm{~mm})$. These are in accordance with the outcomes presented in a recent meta-analysis, where a mean vertical reduction of $0.78 \mathrm{~mm}$ in the buccal wall and $0.50 \mathrm{~mm}$ on the palatal plate were reported. The bone dimensions of immediate implant sites demonstrated approximately 0.5-1.0 $\mathrm{mm}$ reduction in vertical and horizontal aspects 4-12 months following surgery.

Jung et $\mathrm{al}^{(30)}$ using $\mathrm{CBCTs}$ showed a mean horizontal reduction of $0.6 \mathrm{~mm}$ and a vertical reduction of $1.2 \mathrm{~mm}$ at extraction sites filled with an organic bovine bone with no flap elevation at 6 months of healing. Although immediate implant placement may lead to a similar reduction in width as ridge preservation, it limits the number of surgical interventions and chair time, increasing thereby patients satisfaction. The buccal plate receives blood supply from the periodontal ligament, the bone marrow and the outer periosteum ${ }^{(31)}$.

If we consider that the buccal bone wall in maxillary anterior teeth is in most cases $<1 \mathrm{~mm}$ thick, the bone at this site will be mostly comprised by cortical bone. When a tooth is removed, the blood supply coming from the periodontal ligament disappears and the only remaining reservoir comes from the periosteum. Furthermore, if a flap is raised, this last source vanishes and, as a consequence, the buccal plate may resorb. For this reason, it seems reasonable to hypothesize that: a) a thinner buccal plate at baseline may lead to a more pronounced bone resorption and b) flapless surgeries could minimize bone loss. With respect to the first hypothesis, a 
moderate positive correlation was found between the initial buccal bone plate thickness $1 \mathrm{~mm}$ below the crest and a buccal bone height at 6 months. Thus, the thinner the buccal plate, the more reduction in height was seen ${ }^{(31)}$.

In this study, at $2 \mathrm{~mm}$, flapless group showed a significant lower ridge width change $(0.30 \mathrm{~mm})$ than flap (1.28 mm). Huynh-Ba et al. (2010) also observed a mean buccal bone thickness of $1 \mathrm{~mm}$ but highlighted that in $71 \%$ of the cases it was between $0.5-1 \mathrm{~mm}$. Furthermore, Januario et al ${ }^{(33)}$ registered a mean buccal bone thickness of $0.5-0.6 \mathrm{~mm}$ in maxillary incisors and canines $5 \mathrm{~mm}$ apical to the crest on CBCTs ${ }^{(32)}$.

In this study, buccal bone height, flapless group showed a significant decrease $(0.09 \mathrm{~mm})$ change than flap $(1.13 \mathrm{~mm})$ in the flap group, the buccal plate height decreased $1.03 \mathrm{~mm}$ and ridge width up to $1.37 \mathrm{~mm}$. Meanwhile, in the flapless group, the buccal height remained almost stable $(0.08 \mathrm{~mm}$ difference) and the reduction in ridge width ranged from 0.2 to $0.31 \mathrm{~mm}$.whle in palatal bone height, flapless group showed a significant increased change $(0.91 \mathrm{~mm})$ than flap $(0.21 \mathrm{~mm})$. At the palatal crest, a difference of 0.15 and $0.92 \mathrm{~mm}$ in height was observed in the control and treatment groups, respectively. A more palatal placement of the implants in the flapless group could explain the increased palatal height reduction as well as the greater stability of the buccal wall height in this treatment group ${ }^{(34)}$.

Greater combined ridge loss, of $2 \mathrm{~mm}$, was reported 4 months following flap-involving immediate implantation, in spite of grafting of the peri-implant gap .Blanco et al., ${ }^{(35)}$ assessed the marginal soft tissue healing process after flap or flapless surgery in immediate implant placement in a dog model. The clinical evaluation of immediate implant placement after 3 months of healing indicated that buccal soft tissue retraction was lower in the flapless group than in the flap group, without significant differences. The mean values of the biological width longitudinal dimension at the buccal aspect were higher in the flap group than in the flapless group, this difference being mostly because of a thinner biotype in this region ${ }^{(36)}$.

Wadhwa et al., ${ }^{(37)}$ evaluated and compared the effect of flapless and "open flap" techniques of implant placement on crestal bone height $(\mathrm{CBH})$ around implants. Both techniques showed a reduction in $\mathrm{CBH}$ with time but the flapless technique showed a lesser reduction. Therefore, the flapless technique can be considered as a better treatment approach for placement of implants, especially where adequate width and height of available bone are present.

On the contrary, some other studies have found no significant differences in bone level changes between the two surgical protocols. Caneva et al ${ }^{(38)}$ compared the remodeling of the alveolar process at implants installed immediately into extraction sockets by applying a flap or a "flapless" surgical approach in a dog model. "Flapless" implant placement into extraction sockets did not result in the prevention of alveolar bone resorption and did not affect the dimensional changes of the alveolar process following tooth extraction when compared with the usual placement of implants raising mucoperiosteal flaps. Furthermore, Froum et al. ${ }^{(39)}$ found similar mesial and distal bone levels measured on standardized periapical radiographs in flap and flapless groups at 6 months and 1 year after placing one-piece implants.

Stoupel et al, ${ }^{(40)}$ compared the effect of flapless (FLS) or flap involving (F) immediate placement and provisionalization of single-tooth implants in the aesthetic zone in comparable remodeling of the peri-implant mucosa, interproximal bone and buccal ridge at 6 and 12 months.

Mazzoccoet al., ${ }^{(41)}$ evaluate bone dimensions after immediate implant placement with simultaneous 
grafting of the buccal gap, to determine if initial buccal bone width had an influence on bone remodeling and to compare bone volume changes using a flap or a flapless approach after 6 months of healing. A mean reduction of around $0.5 \mathrm{~mm}$ in height and width after placing immediate implants and filling the residual gap with an organic bovine bone may be expected. No significant association between initial buccal bone width and ridge width at 6 months was seen. No statistically significant differences were found between the two treatment protocols although more ridge reduction was observed for the flap group.

Flapless group showed significant higher implant stability than flap. Jeong et al. ${ }^{(42)}$ conducted a study on dogs and reported that flapless implant surgery increases the vascularity of per implant mucosa and, therefore, increases the initial stability of an implant in comparison to implant placed after reflection of the mucoperiosteal flap.

In summary, the flap groups had deacreased reduction in height and width after placing immediate implants and filling the residual gap with an organic bovine bone. Due the existing controversy in the literature, further randomized clinical trials are needed to elucidate this question.

\section{CONCLUSION}

According to the results of this study could concluded that the flapless technique has been documented to be a simpler procedure as compared to "open flap" technique which preserve alveolar bone with immediate dental implants in the esthetic zone of the maxilla of implant after tooth extraction. Also, several advantages achieved by flapless technique such as preservation of soft tissue architecture, intact periosteum maintains a better blood supply, thus reducing the likelihood of early bone resorption or promitting bone healing.

\section{REFERENCES}

1. Mazzocco F, Jimenez D, Barallat L, Paniz G, Fabbro MD Nart J. Bone volume changes after immediate implant placement with or without flap elevation.Clin. Oral Impl Res. 2016; 28: 1-7.

2. James R. introduction to implant dentistry: student guidJ Oral Maxillofac.Surg. 2017; 75:1-100.

3. Scala R, Ghensi P, Cucchi A, Pistoia E. Post extraction Implant Placement with Immediate Provisionalisation and Finalization, Using a Simplified Technique: Technical Notes and a Case Report. Open Dent J.2012; 6: 164-69.

4. Van der Weijden F, Dell'Acqua F, Slot D E. Alveolar bone dimensional changes of post-extraction sockets in humans: a systematic review. J. Clin. Periodontol.2009; 36:1048-58.

5. Tan WL, Wong TLT, Wong MCM, Lang NP. A systematic review of post-extraction alveolar hard and soft tissue dimensional changes in humans. Clin. Oral. Impl. 2012; 23:1-21.

6. Zuffetti F, Capelli M, Galli F, Fabbro M, Testori T. Postextraction implant placement into infected versus non-infected sites: A multicenter retrospective clinical study. Clin Implant Dent Relat Res.2017; 19:1-8.

7. Lee C-T, Chiu T-S, Chuang S-K, Tarnow D, Stoupel J. Alterations of the bone dimension following immediate implant placement into the extraction socket: systematic review and meta-analysis. J Clin Periodontol 2014; 41: 914-26.

8. Schulte $\mathrm{W}$, Heimke G. The T€ubinger immediate implant. Quintessenz.1976; 27:17-23.

9. Januario AL, DuarteWR, Barriviera M, Mesti JC, Araujo M G, Lindhe J. Dimension of the facial bone wall in the anterior maxilla: a cone-beam computed tomography study. Clin. Oral Impl. Res.2011; 22: 1168-71.

10. Paolantonio M, Dolci M, Scarano A, d'Archivio D, di Placido G., Tumini V, et al. Immediate implantation in fresh extraction sockets. A controlled clinical and histological study in man. J Periodontol. 2001; 72: 1560-71.

11. Botticelli D, Persson LG, Lindhe J, Berglundh T. Bone tissue formation adjacent to implants placed in fresh extraction sockets: an experimental study in dogs. Clin. Oral Impl. Res. 2006; 17: 351-58.

12. Botticelli D, Berglundh T, Lindhe J. Hard-tissue alterations following immediate implant placement in extraction sites. J Clin Periodontol. 2004; 31: 820-28 
13. Brownfield LA, Weltman R L. Ridge preservation with or without an osteoinductive allograft: a clinical, radiographic, micro-computed tomography, and histologic study evaluating dimensional changes and new bone formation of the alveolar ridge. J Periodontol. 2012; 83: 581-89.

14. Araujo MG, Lindhe J. Dimensional ridge alterations following tooth extraction. An experimental study in the dog. J Clin Periodontol 2005; 32:212-18.

15. Araujo MG, Sukekava F, Wennstrom JL, Lindhe J. Ridge alterations following implant placement in fresh extraction sockets: An experimental study in the dog. J Clin Periodontol 2005; 32:645-52.

16. Stephen TC, Ivan BD, Eric CR, and John GC. Case series Immediate Implant Placement Postextraction without Flap Elevation.J Clin Periodontol. 2009;80:163-72

17. Blanco J, Nunez V, Aracil L., Munoz F, Ramos I. Ridge alterations following immediate implant placement in the dog: flap versus flapless surgery J Clin Periodontol 2008; 35: 640-48.

18. Van der Zee E, Oosterveld P, Van Waas MA. Effect of GBR and fixture installation on gingiva and bone levels at adjacent teeth. Clin Oral Implants Res 2004; 15:62-5.

19. Campelo LD, Camara JR. Flapless implant surgery: a 10year clinical retrospective analysis. Int J Oral Maxillofac Implants 2002; 17:271-6

20. Sclar AG. Guidelines for flapless surgery. J Oral Maxillofac Surg 2007; 65:20-32.

21. Auty C, Siddiqui A. Punch technique for preservation of interdental papillae at nonsubmerged implant placement. Implant Dent 1999; 8(2):160-6.

22. Salinas TJ. Soft tissue punch technique for aesthetic implant dentistry. Pract Periodontics Aesthet Dent 1998; 10:434.

23. Landsberg CJ, Bichacho N. Implant placement without flaps--Part 2: Utilizing a two-stage surgical protocol. Pract Periodontics Aesthet Dent 1999; 11:169-76.

24. Rocci A, Martignoni M, Gottlow J. Immediate loading in the maxilla using flapless surgery, implants placed in predetermined positions, and prefabricated provisional restorations: a retrospective 3-year clinical study. Clin Implant Dent Relat Res 2003; 5:29-36.

25. Hahn J. Single-stage, immediate loading, and flapless surgery. J Oral Implantol 2000; 26:193-8.
26. Hermann JS, Cochran DL, Nummikoski PV, Buser D. Crestal bone changes around titanium implants. A radiographic evaluation of unloaded nonsubmerged and submerged implants in the canine mandible. J Periodontol 1997; 68:1117-30.

27. Albrektsson T, Zarb G, Worthington P, Eriksson AR. The long-term efficacy of currently used dental implants: a review and proposed criteria of success. Int J Oral Maxillofac Implants 1986; 1:11-25.

28. Pham AN, Fiorellini JP, Paquette D, Williams RC, Weber HP. Longitudinal radiographic study of crestal bone levels adjacent to nonsubmerged dental implants. J Oral Implantol 1994; 20:26-34.

29. Grunder U, Gracis S, Capelli M. Influence of the 3-D bone-to-implant relationship on esthetics. Int J Periodontics Restorative Dent 2005; 25:113-9.

30. Jung RE, Philipp A, Annen BM, Signorelli L, Thoma DS, Hämmerle $\mathrm{CH}$, et al. Radiographic evaluation of different techniques for ridge preservation after tooth extraction: a randomized controlled clinical trial. J Clin Periodontol 2013; 40:90-8

31. Carranza FA, Itoiz ME, Cabrini RL, Dotto CA. A study of periodontal vascularization in different laboratory animals. J Periodontal Res 1966; 1:120-8.

32. Huynh-Ba G, Pjetursson BE, Sanz M, Cecchinato D, Ferrus $\mathrm{J}$, Lindhe $\mathrm{J}$, et al. Analysis of the socket bone wall dimensions in the upper maxilla in relation to immediate implant placement. Clin Oral Implants Res 2010; 21:37-42.

33. Januário AL, Duarte WR, Barriviera M, Mesti JC, Araújo MG, Lindhe J. Dimension of the facial bone wall in the anterior maxilla: a conebeam computed tomography study. Clin Oral Implants Res 2011; 22:1168-71.

34. Tomasi C, Sanz M, Cecchinato D, Pjetursson B, Ferrus J, Lang NP, et al. Bone dimensional variations at implants placed in fresh extraction sockets: a multilevel multivariate analysis. Clin Oral Implants Res 2010; 21:30-6.

35. Koh RU, Oh TJ, Rudek I, Neiva GF, Misch CE, Rothman ED, et al. Hard and soft tissue changes after crestal and subcrestal immediate implant placement. J Periodontol 2011; 82:1112-20

36. Blanco J, Alves CC, Nuñez V, Aracil L, Muñoz F, Ramos I. Biological width following immediate implant placement in the dog: flap vs. flapless surgery. Clin Oral Implants Res 2010; 21:624-31. 
37. Wadhwa B, Jain V, Bhutia O, Bhalla AS, Pruthi G Flapless versus open flap techniques of implant placement: A 15-month follow-up study. Indian J Dent Res 2015; 26:372-7.

38. Caneva M, Botticelli D, Salata LA, Souza SL, Bressan E, Lang NP. Flap vs. "flapless" surgical approach at immediate implants: a histomorphometric study in dogs. Clin Oral Implants Res 2010; 21:1314-9.

39. Froum SJ, Cho SC, Elian N, Romanos G, Jalbout Z, Natour $\mathrm{M}$, et al. Survival rate of one-piece dental implants placed with a flapless or flap protocol--a randomized, controlled study: 12-month results. Int J Periodontics Restorative Dent 2011; 31:591-601.
40. Stoupel J, Lee CT, Glick J, Sanz-Miralles E, Chiuzan C, Papapanou PN. Immediate implant placement and provisionalization in the aesthetic zone using a flapless or a flap-involving approach: a randomized controlled trial. J Clin Periodontol 2016; 43:1171-9.

41. Mazzocco F, Jimenez D, Barallat L, Paniz G, Del Fabbro M, Nart J. Bone volume changes after immediate implant placement with or without flap elevation. Clin Oral Implants Res 2017; 28:495-501.

42. Jeong SM, Choi BH, Kim J, Xuan F, Lee DH, Mo DY, et al. A 1-year prospective clinical study of soft tissue conditions and marginal bone changes around dental implants after flapless implant surgery. Oral Surg Oral Med Oral Pathol Oral Radiol Endod 2011; 111:41-6. 